\title{
Immunohistochemical Analysis of P63 Expression in Odontogenic Lesions
}

\author{
Saede Atarbashi Moghadam, ${ }^{1}$ Fazele Atarbashi Moghadam, \\ Sepideh Mokhtari, ${ }^{1}$ and Ebrahim Eini ${ }^{3}$ \\ ${ }^{1}$ Department of Oral and Maxillofacial Pathology, Dental School of Shahid Beheshti University of Medical Sciences, Tehran, Iran \\ ${ }^{2}$ Department of Periodontology, Dental School of Sadoughi University of Medical Sciences, Yazd, Iran \\ ${ }^{3}$ Research Committee, Jundishapur University of Medical Sciences, Ahvaz, Iran \\ Correspondence should be addressed to Sepideh Mokhtari; sepidemokhtary@yahoo.com
}

Received 19 September 2013; Accepted 27 October 2013

Academic Editor: Takashi Saku

Copyright (C) 2013 Saede Atarbashi Moghadam et al. This is an open access article distributed under the Creative Commons Attribution License, which permits unrestricted use, distribution, and reproduction in any medium, provided the original work is properly cited.

\begin{abstract}
P63 may have a role in tumorigenesis and cytodifferentiation of odontogenic lesions. We investigated the immunohistochemical expression of P63 in a total of 30 cases of odontogenic cysts and tumors. The percentage of positive cells was calculated in the lining of odontogenic cysts and islands of ameloblastoma. P63 expression was evident in all types of odontogenic lesions. P63 was expressed throughout the lining epithelium of odontogenic keratocyst except surface parakeratinized layer. In addition, calcifying odontogenic cyst showed P63 expression in all layers. In almost all radicular and dentigerous cysts, the basal and parabasal layers were immunoreactive. Peripheral cells of ameloblastoma expressed P63; however, stellate reticulum had weaker immunostaining. No significant difference in P63 expression was observed between studied lesions $(P=0.86)$. Expression of P63 in odontogenic lesions suggests that this protein is important in differentiation and proliferation of odontogenic epithelial cells. However, it seems that it could not be a useful marker to differentiate between aggressive and nonaggressive lesions. P63 also represents a progenitor or basal cell marker, and it is not expressed in mature differentiated cells.
\end{abstract}

\section{Introduction}

P63 is a member of P53 gene family, which has a role in epithelial development, stem cell biology, and carcinogenesis [1]. P63 is also expressed in odontogenic epithelium [2,3]. To date, only few papers have studied the expression of this protein in odontogenic lesions [4]. It seems that the epithelial cells of aggressive odontogenic lesions have some intrinsic growth potential not present in other odontogenic lesions [5]. Therefore, understanding the pathogenesis and biological aspects of these lesions would improve the success in diagnosis and treatment procedures [6]. In this paper, we investigated the expression of P63 in various odontogenic lesions.

\section{Materials and Methods}

We studied the expression of P63 in 30 odontogenic lesions: 9 odontogenic keratocysts (OKC), 6 ameloblastoma,
6 radicular cysts (RC), 6 dentigerous cysts (DC), and 3 calcifying odontogenic cysts (COC). All were primary lesions. Histopathological diagnosis was confirmed by an experienced pathologist using H\&E stained sections. Clinical data were recorded. The expression of $\mathrm{P} 63$ was determined by immunohistochemical staining (streptavidin-biotin peroxidase method) on paraffin sections using microwave antigen retrieval method. P63 monoclonal antibody, clone 4A4, Code N 1604, 1:25 dilution, Dako Cytomation, Denmark, was used. We used clone 4A4 that recognizes the $\triangle \mathrm{NP} 63$ isoforms. The sections were incubated with primary antibody at $4^{\circ} \mathrm{C}$ overnight. Squamous cell carcinoma was used as positive control. For negative control, the primary antibody was replaced by a nonimmune serum. Some representative fields were randomly selected in each stained section using Olympus CX21 light microscope. Ten fields were chosen for each section. Only nuclear staining of epithelial cells was 


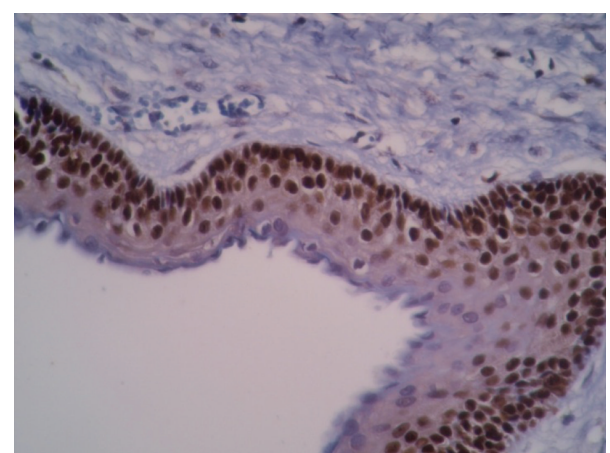

FIGURE 1: P63 is highly expressed as brown nuclei in OKC throughout the epithelial lining except parakeratinized layer $(\times 200)$.

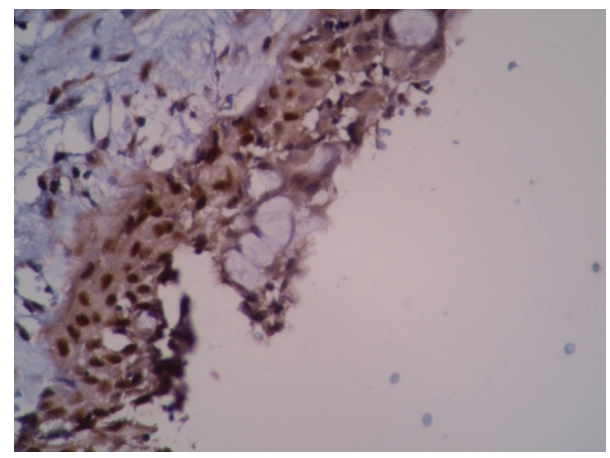

FIgURE 2: Dentigerous cyst with high expression of P63 in almost all epithelial layers. Mucous cells in the epithelial lining do not show any reaction $(\times 200)$.

TABle 1: P63 expression in odontogenic lesions. No significant difference was observed between studied lesions $(P=0.86)$.

\begin{tabular}{lccc}
\hline Pathologic lesion & $N$ & Mean & \pm SD \\
\hline OKC & 9 & 98.33 & 2.5 \\
AB & 6 & 86.42 & 22.56 \\
RAD & 6 & 93.08 & 13.80 \\
DC & 6 & 93.75 & 10.46 \\
COC & 3 & 96.67 & 5.77 \\
\hline
\end{tabular}

considered positive. The percentage of positive cells was calculated (In HPF) from a minimum of 1000 epithelial cells in basal-parabasal and upper layers of cysts and islands of ameloblastoma.

SPSS software (version 16) was used, and the results were analyzed with Kruskal-Wallis and Mann-Whitney tests. Statistical significance was at $P<0.05$.

\section{Results}

P63 was expressed in all studied cases $(n=30)$. All lesions showed intense reactivity in odontogenic epithelium (Table 1). Immunostaining was found throughout the epithelial lining of $\mathrm{OKC}$ except the surface parakeratinized layer (Figure 1). In DCs, RCs mostly the basal and parabasal layers were positive for P63 (Figures 2, 3, and 4). Four cases of

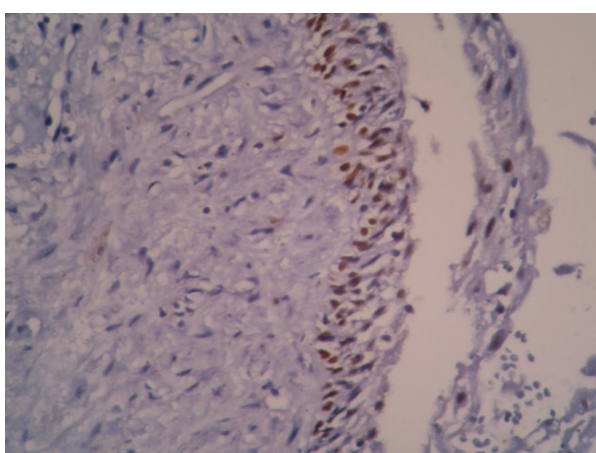

FIgURE 3: P63 expression in radicular cyst. Intense reactivity in basal and parabasal layers $(\times 200)$.

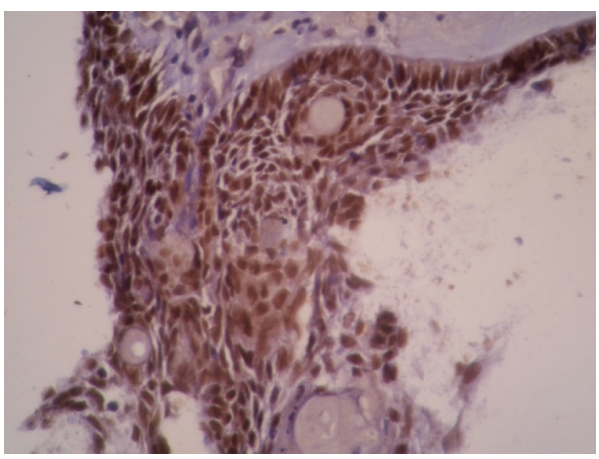

Figure 4: P63 expression in calcifying odontogenic cyst $(\times 200)$. Ghost cells do not express this protein.

DCs also demonstrated intense reactivity in upper layers. No to weak reactivity was seen in the upper layers of RC. In addition, COC cases were immunostained in all layers of cyst. Ameloblastoma was intensely positive in peripheral cells. However, the reactivity in the stellate reticulum was weaker (Figure 5). With Kruskal-Wallis test no significant difference in the expression of P63 was observed between the lesions $(P=0.86)$. Mann-Whitney test revealed that there is significant difference between basal-parabasal and upper layers in odontogenic cysts $(P<0.001)$. Normal oral epithelium in sections also had positive immunostaining in basal-parabasal layers. The mucous cells of epithelial lining in DC and ghost cells of COC did not show any reaction to P63.

\section{Discussion}

P63, a member of P53 tumor suppressor gene family, plays a major role in the maintenance of epithelial stem cells and their terminal differentiation. P63 gene generates different protein isoforms (TA and $\Delta \mathrm{N}$ ) with different functions. $\Delta \mathrm{N}$ P63 isoforms (lacking $\mathrm{N}$-terminal transactivation domain) are involved in cell proliferation, while TAP63 isoforms (containing the transactivation domain) have a role in cell differentiation $[2,3]$. In the absence of P63, stem cells and their progenies die by apoptosis, and the crippled stem cells are unable to bolster cell proliferation and self-renewal [7]. 


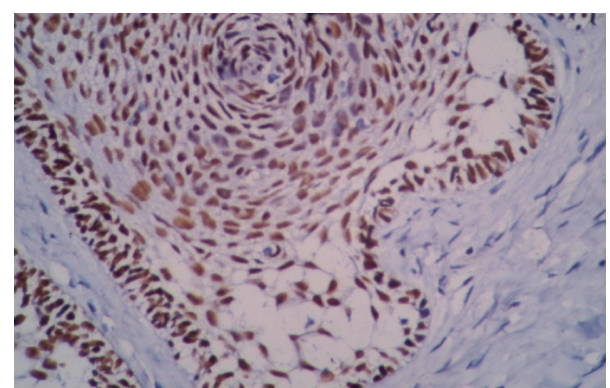

Figure 5: High expression of P63 in ameloblastoma. Peripheral columnar cells show more intense staining than stellate reticulum $(\times 200)$.

Upregulation of P63 has been also demonstrated in some malignancies [3]. In addition, P63 gene expression has been detected in the majority of tooth germ cells and dental epithelium throughout the bud and cap stages [1]. Investigators suggest that P63 is involved in epithelial differentiation during tooth development. Syndromes that are associated with $\mathrm{P} 63$ gene mutation have also various tooth abnormalities [3].

The results of this study is in accordance with other investigations of $\mathrm{P} 63$ expression in $\mathrm{OKC}$ which show positive immunoreactivity in all layers except for parakeratinized layer $[4,5,7]$.

P63 reactivity was also evident in basal-parabasal layers of DC and RC. However, upper layers had weaker expression in these odontogenic cysts. Positivity of the upper layers in RC and DC has been reported to be 3-6\% in other studies [5].

P63 expression in ameloblastoma was more intense in peripheral cells than in stellate reticulum. This finding is in accordance with Kumamoto et al. study [3] and may indicate the higher proliferative activity of peripheral cells in tumor islands of ameloblastoma.

Expression of P63 has been also investigated in other odontogenic lesions. Acanthomatous and granular cell types of ameloblastoma have lower P63 expression than common ameloblastoma [3]. In addition, adenomatoid odontogenic tumor has nuclear positivity for P63 indicating the basal characterization of tumor cells $[8,9]$. Friedrich and Zustin described a case of Pindborg tumor with P63 expression in the vast majority of tumor cells [10]. In addition, Koutlas et al. reported three cases of Sclerosing odontogenic carcinoma with positive nuclear staining against P63 antibody [11]. Moreover, central granular cell odontogenic tumor demonstrates P63 expression in odontogenic epithelial islands. However, granular cells are negative [12]. This finding may indicate that this protein is not expressed in the mature differentiated cells. Gurgel et al. suggest that P63 expression reflects the immaturity of epithelial cells in keratinocytes of OKCs. They also stated that this protein participates in differentiation of epithelial cells [4]. In addition, we did not observe any positive reactivity in the mature keratinocytes of oral epithelium similar to previous studies $[5,13]$. Therefore, it seems that P63 expression is limited to immature basalparabasal layers of epithelium.
Previous investigations show that all neoplastic and nonneoplastic odontogenic tissues express P63 protein [13]. Seyedmajidi et al. reported a higher expression of P63 in OKC than in DC and RC [14]. However, there was no significant difference between various odontogenic lesions in this study, which may be related to the different number of examined lesions in these two studies. Bello et al. also had an investigation of ameloblastoma and ameloblastic carcinoma. They showed that $\mathrm{p} 63$ expression is not significantly different between ameloblastoma and its malignant counterpart [15].

\section{Conclusion}

The expression of P63 in odontogenic cysts and tumors suggests that this protein is involved in differentiation and proliferation of odontogenic epithelial cells. It may also have a crucial role in tooth development. Moreover, P63 as a progenitor or basal cell marker is not expressed in mature cells. Also, it seems that this protein is not a useful marker in differentiation between odontogenic lesions with aggressive and nonaggressive behavior.

\section{Conflict of Interests}

The authors declare that there is no conflict of interests.

\section{References}

[1] A. Brkić, S. Mutlu, H. Koçak-Berberoğlu, and V. Olgaç, "Pathological changes and immunoexpression of p63 gene in dental follicles of asymptomatic impacted lower third molars: an immunohistochemical study," Journal of Craniofacial Surgery, vol. 21, no. 3, pp. 854-857, 2010.

[2] M. P. Foschini, R. Cocchi, G. Marucci et al., "High $\Delta \mathrm{N}$ p63 isoform expression favours recurrences in odontogenic keratocystodontogenic keratocystic tumour," International Journal of Oral and Maxillofacial Surgery, vol. 35, no. 7, pp. 673-675, 2006.

[3] H. Kumamoto, K. Ohki, and K. Ooya, "Expression of p63 and p73 in ameloblastomas," Journal of Oral Pathology and Medicine, vol. 34, no. 4, pp. 220-226, 2005.

[4] C. A. S. Gurgel, E. A. G. Ramos, R. A. Azevedo, V. A. Sarmento, A. M. Da Silva Carvalho, and J. N. Dos Santos, "Expression of $\mathrm{Ki}-67, \mathrm{p} 53$ and $\mathrm{p} 63$ proteins in keratocyst odontogenic tumours: an immunohistochemical study," Journal of Molecular Histology, vol. 39, no. 3, pp. 311-316, 2008.

[5] L. Lo Muzio, A. Santarelli, R. Caltabiano et al., "p63 expression in odontogenic cysts," International Journal of Oral and Maxillofacial Surgery, vol. 34, no. 6, pp. 668-673, 2005.

[6] B. Sengüven and T. Oygür, "Investigation of interleukin-1 alpha and interleukin- 6 expression and interleukin-1 alpha gene polymorphism in keratocystic odontogenic tumors and ameloblastomas," Medicina Oral, Patologia Oral y Cirugia Bucal, vol. 16, no. 4, pp. e467-e472, 2011.

[7] Q. Dong, S. Pan, L. S. Sun, and T. J. Li, "Orthokeratinized odontogenic cyst A clinicopathologic study of 61 cases," Archives of Pathology and Laboratory Medicine, vol. 134, no. 2, pp. 271275, 2010.

[8] F. J. Vera Sempere, M. J. Artes Martínez, B. Vera Sirera, and J. Bonet Marco, "Follicular adenomatoid odontogenic tumor: immunohistochemical study," Medicina Oral, Patología Oral y Cirugía Bucal, vol. 11, no. 4, pp. E305-E308, 2006. 
[9] R. E. Friedrich, H. A. Scheuer, and J. Zustin, "Adenomatoid odontogenic tumor (AOT) of maxillary sinus: case report with respect to immunohistochemical findings," In Vivo, vol. 23, no. 1, pp. 111-116, 2009.

[10] R. E. Friedrich and J. Zustin, "Calcifying epithelial odontogenic tumour of the maxilla: a case report with respect to immunohistochemical findings," In Vivo, vol. 25, no. 2, pp. 259-264, 2011.

[11] I. G. Koutlas, C. M. Allen, G. R. Warnock, and J. C. Manivel, "Sclerosing odontogenic carcinoma: a previously unreported variant of a locally aggressive odontogenic neoplasm without apparent metastatic potential," American Journal of Surgical Pathology, vol. 32, no. 11, pp. 1613-1619, 2008.

[12] A. T. M. Mesquita, C. R. R. Santos, R. S. Gomez, J. Jorge, J. E. León, and O. P. de Almeida, "Central granular cell odontogenic tumor: a histopathologic and immunohistochemical study," Annals of Diagnostic Pathology, vol. 13, no. 6, pp. 405-412, 2009.

[13] D. Gratzinger, M. E. Salama, C. F. Poh, and R. V. Rouse, "Ameloblastoma, calcifying epithelial odontogenic tumor, and glandular odontogenic cyst show a distinctive immunophenotype with some myoepithelial antigen expression," Journal of Oral Pathology and Medicine, vol. 37, no. 3, pp. 177-184, 2008.

[14] M. Seyedmajidi, S. Shafaee, E. Shafigh, A. Bijani, and H. Hamidi, "p63 expression in randomized odontogenic cysts," Saudi Medical Journal, vol. 32, no. 5, pp. 463-466, 2011.

[15] I. O. Bello, K. Alanen, P. J. Slootweg, and T. Salo, "Alphasmooth muscle actin within epithelial islands is predictive of ameloblastic carcinoma," Oral Oncology, vol. 45, no. 9, pp. 760$765,2009$. 


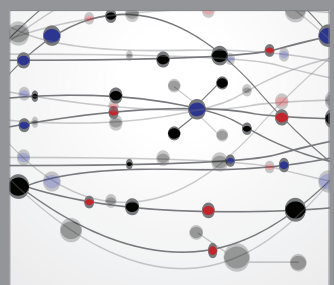

The Scientific World Journal
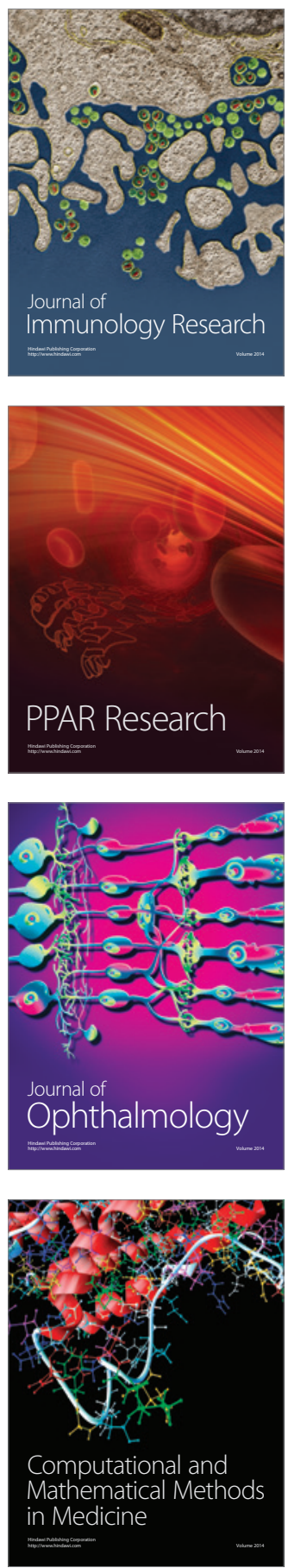

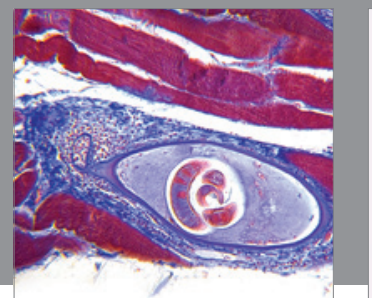

Gastroenterology

Research and Practice
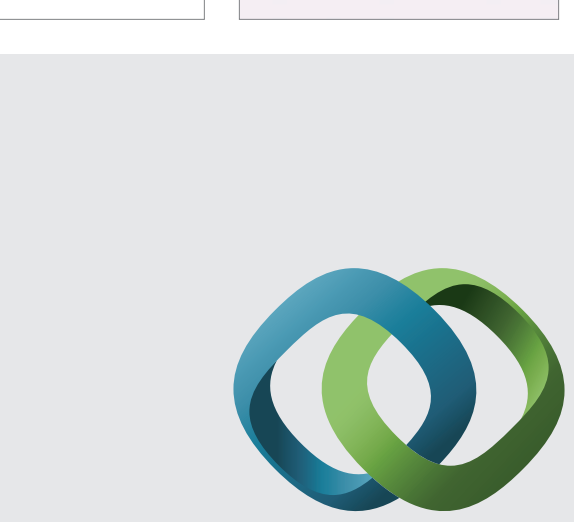

\section{Hindawi}

Submit your manuscripts at

http://www.hindawi.com
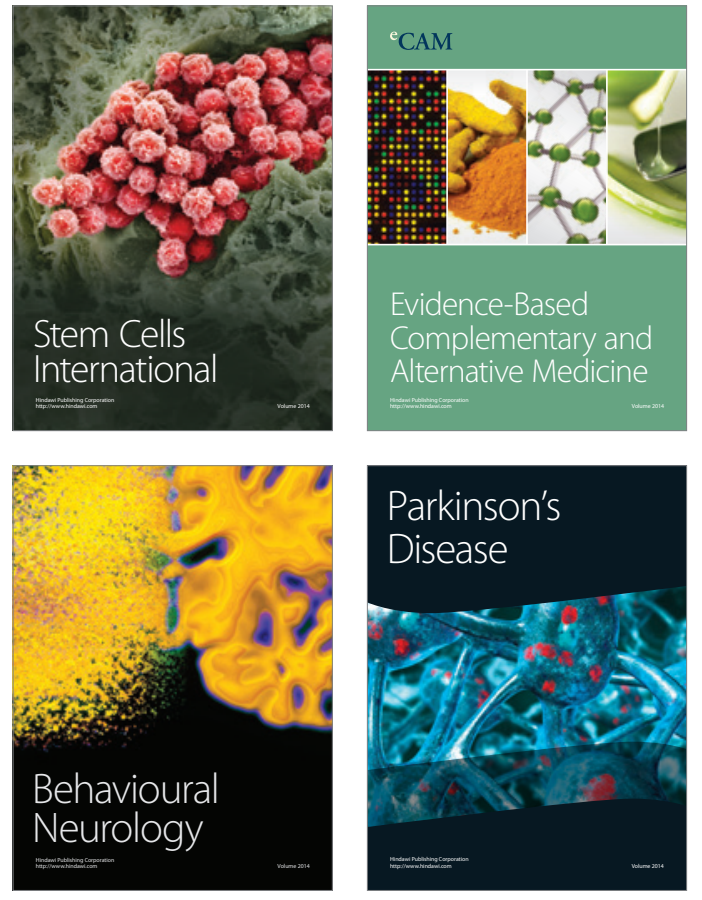
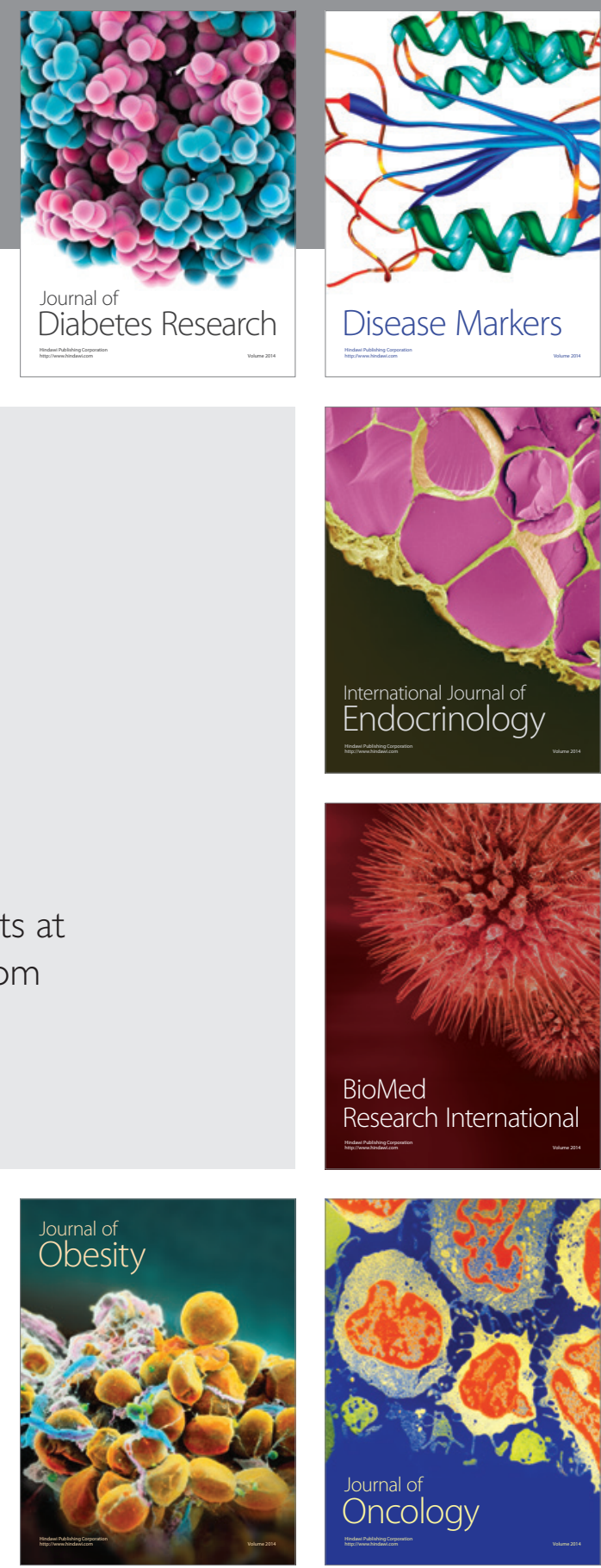

Disease Markers
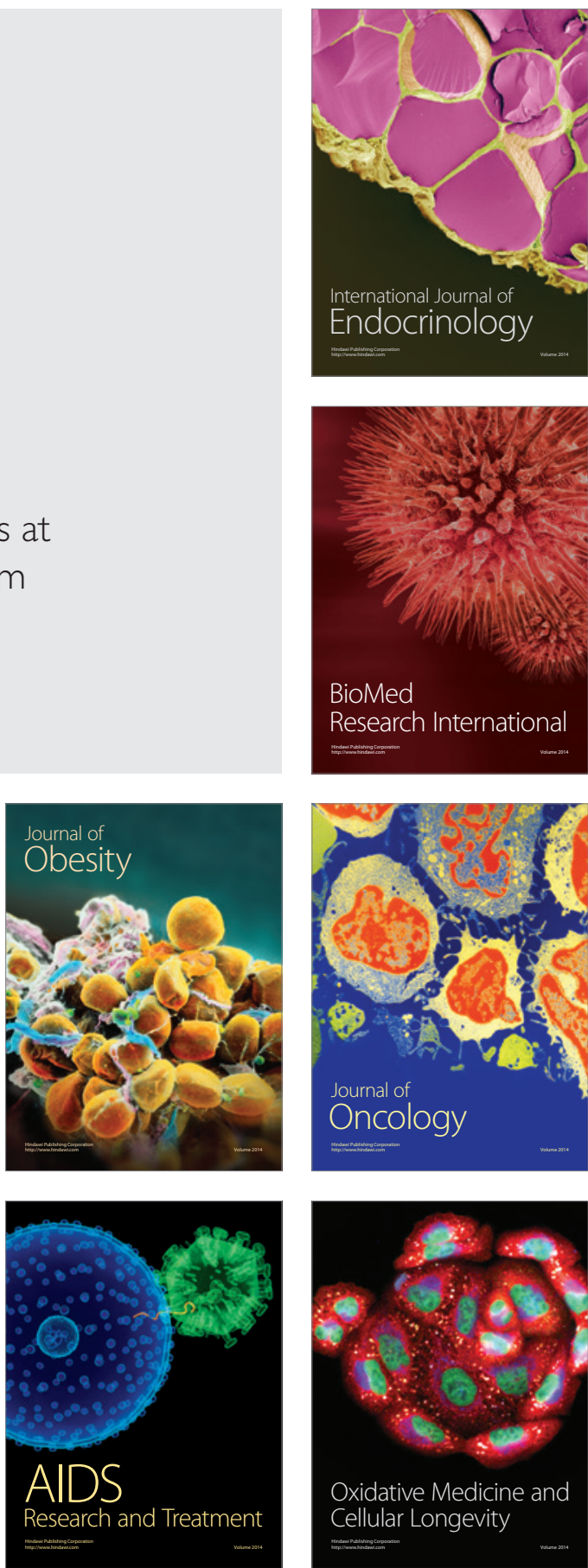